\title{
Exocrine Pancreatic Cancer pTX TNM
}

\section{Finding v6}

National Cancer Institute

\section{Source}

National Cancer Institute. EXocrine Pancreatic Cancer pTX TNM Finding V6. NCI

Thesaurus. Code C60941.

Exocrine pancreatic cancer in which the primary tumor cannot be assessed. (from AJCC 6th Ed.) 